\title{
O LÚDICO E SUA RELAÇÃO COM AS METODOLOGIAS ATIVAS: REFLEXÃO ACERCA DAS POSSIBILIDADES DO FAZER PEDAGÓGICO
}

\author{
Juliana Marques Paiva de Souza ${ }^{\mathrm{i}}$ \\ Marco Antonio Santoro Salvador ${ }^{\text {ii }}$
}

\begin{abstract}
Resumo: O presente artigo é um recorte de uma investigação de mestrado já finalizada e tem como objetivo proporcionar uma reflexão acerca da relação entre o lúdico e as metodologias ativas no que tange às práticas educativas. Para tal, apresenta os aspectos inerentes aos conceitos de lúdico e metodologias ativas de modo a viabilizar o debate sobre as práticas pedagógicas. Com base na revisão bibliográfica concluiu-se que a pesquisa acerca do lúdico e das metodologias ativas no contexto pedagógico poderá estimular a incorporação de práticas ativas nas aulas das diversas disciplinas da Educação Básica, tornando a aprendizagem mais prazerosa, promovendo a construção de propostas de ensino que visem a superação da passividade dos alunos, permitindo a construção coletiva e a expressão das identidades ali presentes.
\end{abstract}

Palavras-chave: Lúdico; Educação; Aprendizagem ativa; Metodologias ativas.

\section{JUEGO Y SU RELACIÓN CON METODOLOGÍAS ACTIVAS: REFLEXIÓN SOBRE LAS POSIBILIDADES DEL HACER PEDAGÓGICO}

Resumen: Este artículo es un recorte de la investigación de un maestro y tiene como objetivo proporcionar una reflexión sobre la relación entre las metodologías lúdicas y activas con respecto a las prácticas educativas. Para ello, presenta los aspectos inherentes al concepto de lúdico y metodologías activas para permitir el debate sobre prácticas pedagógicas. Con base en la revisión de la literatura, se concluyó que la investigación sobre las metodologías lúdicas y activas en el contexto pedagógico puede estimular la incorporación de prácticas activas en las clases de las diversas materias de Educación Básica, haciendo que el aprendizaje sea más agradable. Fomentar la construcción de propuestas docentes encaminadas a superar la pasividad de los alumnos, permitiendo la construcción colectiva y la expresión de las identidades presentes allí.

Palabras clave: Juguetón; Educación; Aprendizaje activo; Metodologías activas.

\section{Introdução}

Em tese, a escola como conhecemos atualmente, apresenta-se como uma instituição de ensino organizada de modo a propor um ambiente dito como ideal para a aquisição do conhecimento. Entretanto, o que se observa no seu cotidiano, é um cerceamento demasiado do 


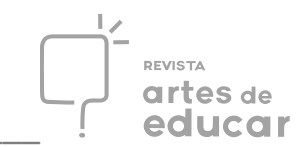

corpo, que acaba por corromper parte da natureza lúdica do aluno. Ao entrar na escola, normalmente, ele se depara com uma estrutura física e hierárquica geralmente rígida que inibe ou até mesmo proíbe a sua livre expressão.

Na perspectiva de Foucault (1999), o homem moderno nasce diante minuciosas ações coercitivas. No ambiente escolar, tais ações são concretizadas por meio de uma rotina controladora que resulta na promoção dos corpos adestrados.

A organização temporal da escola apresenta-se, também, como uma ferramenta de controle que tem seu registro na grade horária, preenchida por uma extensa gama de atividades a serem realizadas, sem permitir que o aluno tenha um momento reservado para a sua livre expressão por meio de atividades lúdicas. Ao entrar na escola o aluno deixa o riso, as cores, o dinâmico e o ruído do lado de fora (GOMES, 2009).

Nessa premissa, Foucault (1999) compara a sala de aula com uma cela, como um local de sequestro, onde parte da individualidade dos alunos é suprimida por meio de condutas disciplinadoras.

Tais condutas reforçam a homogeneização dos indivíduos que circundam este ambiente, no qual se espera a reprodução de comportamentos pré-estabelecidos pela sociedade. Quanto à negação do corpo, Oliveira (2006) afirma que:

Ao analisar as práticas corporais na escola, percebemos um constante esforço de negação do corpo. Negação esta que se manifesta mediante um controle intenso sobre toda e qualquer ação, seja de professores, alunos e funcionários, alimentado por uma certa previsibilidade daquilo que ocorre, ou daquilo que pode ocorrer, em termos corporais, no interior da escola (p.57).

Esse contexto afere à escola uma característica pouco agradável aos que ali estão, tornando-a, por muitas vezes, um ambiente triste, sem cor, sem atrativo e desmotivante, a não ser nos momentos de relativa liberdade, tais como o recreio e a aula de Educação Física. Nesses momentos, dependendo da proposta pedagógica do professor, é possível vivenciar sua plenitude através de atividades lúdicas corporais que coadunam com as experiências dos alunos.

Betti (1992) nos diz que aprendemos pelo prazer. Seguindo essa lógica, podemos dizer que as proibições presentes no cotidiano escolar tendem a diminuir o prazer de estar na escola influenciando de maneira negativa no processo de aprendizagem. 
Parece haver descompasso entre as características dos alunos e as da escola, uma possível falta de comunicação entre as vivências intra e extra escolares, como se o que acontecesse na vida pessoal não pudesse interferir ou relacionar-se com os conhecimentos pedagógicos.

Esta falta de diálogo poderá fazer com que as práticas pedagógicas ali realizadas não tenham significado para os alunos, tornando-as desmotivantes. Esta situação agrava-se no mundo globalizado marcado pelas múltiplas conexões que geram a propagação das informações numa velocidade quase incomensurável. $\mathrm{O}$ aluno da sociedade hodierna possui um pensamento complexo capaz de interligar os diversos saberes adquiridos nas suas experiências de vida.

Com relação a isto, Libâneo et. al (2012) afirmam que

Se a escola tem por finalidade a apropriação dos saberes sistematizados e o desenvolvimento de capacidades intelectuais, sua atenção deve voltar-se para a aprendizagem dos alunos, a qual depende não apenas da mediação do ensino, mas também da consideração do contexto socioeconômico-cultural dos estudantes, das expectativas sociais das famílias, dos processos de organização e gestão da escola, da participação efetiva da comunidade, das práticas curriculares e processos pedagógico-didáticos, das formas de avaliação tanto do funcionamento da escola como das aprendizagens dos alunos (p. 250-251).

Diante disso, é preciso repensar as práticas exercidas no interior das instituições de ensino, de forma a propor o aprender a aprender (MORIN, 2014), auxiliando o aluno no gerenciamento das informações às quais se tem acesso, de modo a organizar e construir sua própria perspectiva.

Neste sentido, Libâneo (1994), acrescenta que

Por outro lado, essa compreensão do trabalho docente requer um professor capaz de encarar sua tarefa como parte da prática social global, para o que precisa adquirir um conhecimento teórico que lhe permita pensar e agir sobre o real histórico e, também, dominar os meios operacionais: o saber e o saberfazer didáticos (p. 128).

Atividades lúdicas desenvolvidas de maneira contextualizada podem ser uma alternativa para uma renovação das práticas pedagógicas. Contudo, vale ressaltar que o lúdico não está presente apenas nos jogos praticados nas aulas de Educação Física, pois segundo 
Vial (2015) atividades de música, teatro, cinema, fotografia, dentre outras, constituem-se diferentes jogos e expressam o lúdico em sua vivência.

O jogo, seja ele qual for, apresenta-se como uma possibilidade de atuação lúdica numa prática pedagógica pautada na aprendizagem ativa. Visto que, para Vial (2015) O jogo requer uma verdadeira estratégia, isto é, um projeto lúdico [...], ou seja, durante o jogo é preciso unir diferentes habilidades e conhecimentos de modo a refletir sobre eles, criando um projeto de atuação que propiciará o sucesso de sua realização.

Nessa perspectiva, a integração do lúdico às práticas educativas poderia embasar uma proposta de ensino que visasse romper com a passividade dos alunos, permitindo a construção coletiva e a expressão das identidades ali presentes.

\section{O lúdico no contexto escolar}

A sociedade hodierna vem sendo surpreendida com novas tecnologias numa velocidade avassaladora. Em curtos períodos de tempo são lançados novos mecanismos digitais que possibilitam uma maior interação entre pessoas de diversas partes do mundo, gerando, consequentemente, um diálogo maior entre os pares, numa constante troca de experiências. Assim, o jovem em seu cotidiano se mantém conectado às diversas redes sociais compartilhando e recebendo informações de diversos setores. Mas será que esse jovem está preparado para interagir e refletir acerca desse bombardeio informativo? Sendo esse jovem um estudante do ensino básico, estaria a escola preparada para lidar com essa demanda?

Pensamos que tais questões sejam pertinentes, pois, é necessário ter cautela ao se defrontar com a diversidade de informações disponíveis que torna indispensável a realização de uma leitura crítica, com um olhar curioso no sentido de pesquisar o que está sendo divulgado e confrontar com outras perspectivas. Nesse sentido, Kilpatrick (2011) nos alerta sobre a necessidade do encorajamento no entendimento do porquê das coisas, pois segundo ele [...] com uma enorme multidão a ser convencida, o pensamento possui um papel muito pequeno. (p. 37).

Contudo, o ato de pesquisar, analisar e comparar é construído e aprimorado com o passar das experiências vividas. Que lugar senão a escola seria o mais indicado para explorar tais vivências, visto que a educação pode ser entendida como a categoria fundamental que 
permite o entendimento da relação entre aprendizagem, desenvolvimento e cultura. (STOLTZ, 2008, p. 76).

Porém, Vial (2015) afirma que a escola produz tarefas morosas e pré-fabricadas: o inesperado é suspeito, o insólito condenado, o riso subversivo e reprimido. (p. 16). Como se houvesse dois mundos - o escolar e o extraescolar - e, ao entrar na instituição de ensino, parte da subjetividade e individualidade tivessem que ser deixados de fora.

Outro aspecto que merece ser levado em pauta refere-se à fragmentação dos conceitos trabalhados na escola. Há uma possível incongruência entre as práticas sociais e as práticas escolares. Isso porque diante de uma sociedade globalizada e interconectada, a escola mantém práticas distintas para cada disciplina, dividindo os conteúdos de acordo com as características dos conceitos abordados. Nesse sentido, Morin (2014) alerta-nos que [...] $a$ hiperespecialização impede de ver o global [...] (p. 13). Ou seja, a forma como a escola vem conduzindo os processos de aprendizagem pode não estar colaborando para que o jovem seja capaz de lidar de maneira crítica com esse bombardeio informativo.

Diante do panorama apresentado, no qual temos uma sociedade interconectada com práticas pedagógicas fragmentadas e tendo como pressuposto o paradigma tradicional de ensino, qual seria a possiblidade mais viável de atuação de modo a minimizar ou até mesmo, numa possível utopia, superar esses conflitos?

Talvez a resposta esteja no ensinar para a vida. Ao pensar nessa premissa fica mais fácil, ou menos difícil, a percepção do papel da escola. Quando se pensa numa educação para a vida é preciso pensar primeiramente qual é o objetivo da escola, seja voltar-se para a formação de um sujeito que reproduz o que lhe foi ensinado ou para a formação de um sujeito que seja capaz de lidar com as imprevisibilidades. Uma vez que, segundo Morin (2014) a maior certeza que nos foi dada é a da indestrutibilidade das incertezas, não somente na ação, mas também no conhecimento. (p. 55).

Nesse sentido, torna-se mais coerente pensar num processo de aprendizagem para a vida, tendo a clareza de não sermos capazes de prever o que virá pela frente - o que reforça a necessidade de estimular a autonomia e a capacidade crítica dos alunos numa crescente construção do pensamento autônomo.

Conceber uma educação consoante com essa perspectiva requer uma mudança da concepção do fazer educativo no qual seja possível uma atuação mais efetiva do aluno num 
processo dialético entre alunos e professores, com vistas a um aprender para a vida em sociedade, por meio de metodologias que permitam a interação entre teoria e prática.

Ao refletir a respeito do cotidiano escolar, percebemos a presença de condutas semelhantes àquelas características do capitalismo - poucos são os momentos de prazer no espaço educativo. No geral, a presença de vivências lúdicas restringe-se às aulas de Educação Física e aos recreios, como se a diversão tivesse hora marcada. Essa ação transmite a mensagem ao aluno de que a sala de aula consiste num ambiente de aprendizagem que necessariamente precisa estar adequado para isso, onde sons, cores e movimentos não são bem-vindos, exceto nos momentos de salvo-conduto.

Dessa forma,

Tradicionalmente a escola mantém o corpo sob controle, pois as suas diversas estratégias metodológicas regularmente apontam para o imobilismo, para a construção do conhecimento priorizado no aspecto cognitivo, pouco atento as expressões corporais e os movimentos construídos pelos alunos, que traduzem um conjunto acumulado de conhecimento, cultura, política e história (SALVADOR, 2007, p. 246).

Ademais, de acordo com Rau (2007) [...] a ausência de jogos e brincadeiras tradicionais na vida cotidiana escolar e familiar faz com que muitas crianças apresentem dificuldades motoras, afetivas e sociais. (p. 55-56).

Gomes (2009) acrescenta ainda que o lúdico está estritamente ligado à existência do sujeito, pois desde a tenra idade são realizadas atividades lúdicas. Ou seja, a criança brinca o tempo todo. E através desse brincar expressa seus saberes e sua subjetividade. Cleomar Ferreira Gomes alerta-nos ainda que a falta do lúdico na escola possa ser um dos motivos pelo qual os alunos já na Educação Infantil apresentem uma rejeição à escola.

Diante dessa perspectiva, acreditamos que não seja coerente a ausência ou até mesmo a negação das práticas educativas lúdicas nas instituições escolares. Afinal, como afirma Vial (2015) seja como for, o tempo imprescritível do recreio não pode bastar. (p. 217). Tendo como base o propósito desta pesquisa, para que possamos debater com mais lucidez, faz-se necessário compreender alguns conceitos referentes ao lúdico.

Tendo como pressuposto os estudos de Luckesi (2002, 2014, 2015), é possível observar que o autor aborda os conceitos de ludicidade, lúdico e vivência lúdica tendo como referencial o sujeito. Assim, [...] denomina de lúdico o estado interno do sujeito e de 


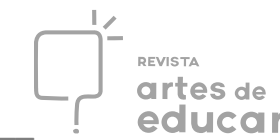

ludicidade a característica de quem está em estado lúdico. (MASSA, 2015, p. 120-121). No que tange às vivências lúdicas é possível constatar que estas [...] serão lúdicas na medida em que estimularem o estado lúdico do indivíduo [...]. (Id., 2015, p. 120).

Diante dessa premissa, há a possibilidade de uma mesma atividade ser lúdica para um aluno e não lúdica para outro de acordo com as suas vivências anteriores, mesmo que essa atividade esteja socialmente associada ao prazer de praticá-la. Ou seja, o lúdico é relativo.

Esta percepção do lúdico como sendo relativo às experiências pessoais pode encontrar um reforço no debate sobre o conceito de lúdico proposto por Vial (2015), no qual o autor demonstra a interdependência dos efeitos de natureza fisiológica, social e psicológica do jogo expressos, por exemplo, na possibilidade do resgate da ancestralidade e na preparação para a vida adulta.

O autor conclui comparando o jogo a um projeto lúdico que requer do jogador a criação de um esquema, uma estratégia diante das vivências de modo a alcançar o objetivo. Para isso, faz uso de competências similares às do processo de aprendizagem ao abordar o crescimento do sujeito por meio da prática do exercício orientado com base nos seus erros e acertos. Apresenta, ainda, uma classificação composta pelas seguintes categorias: jogos educativos, do espírito, dos sentidos e os mais complexos.

O autor inicia sua categorização apresentando os jogos educativos, que são aqueles que convertem o corpo em brinquedo por meio das danças e cirandas; por terem uma movimentação específica obedecendo ao ritmo e à cadência da música pré-estabelecidos, não são considerados totalmente livres. Temos como exemplo as cantigas de roda da cultura popular.

A segunda categoria de jogo tem como eixo central a imaginação e denomina-se jogo do espírito, pois nele a criatividade não tem limite e a imaginação pode vislumbrar aquilo que o real não comporta.

Os jogos dos sentidos compreendem a terceira categoria. Nele estão presentes três subcategorias: os jogos da audição que se utilizam da arte da fala e da escuta com vistas a auxiliar na preparação de bons ouvintes para o mundo da música, de modo a apreciá-la de maneira crítica; os jogos da palavra e do canto equivalem ao coral onde é possível a participação mais efetiva do sujeito tanto na criação quanto na reprodução musical; já os jogos da visão referem-se às leituras de imagens tão importantes quanto à leitura e à escrita de palavras.

Revista Interinstitucional Artes de Educar. Rio de Janeiro, V. 5, N.3- pág. 666-682 set-dez de 2019: "Educação: Corpo em movimento." - DOI: 10.12957/riae.2019.45451 


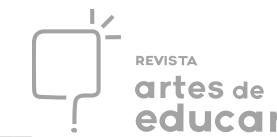

A quarta e última categoria refere-se aos jogos mais complexos, na qual engloba: o lazer-leitura e sua educação que compreende a leitura como uma prática lúdica; o teatro que visa a atuação do aluno na construção e apresentação de peças teatrais contando com o trabalho colaborativo dos colegas; o cinema que refere-se ao cineclube com o propósito de ensinar cinema por meio do olhar crítico; o teleaudiovisual que contempla os programas transmitidos pela televisão e trata do estímulo da reflexão acerca das mensagens recebidas, buscando despertar nos alunos a curiosidade e o olhar atento aos detalhes; o jogo da escrita que aborda a escrita como uma prática lúdica alertando que a obrigatoriedade desta prática pode subtrair dela a alegria inerente à conclusão de um processo de escrita.

Com base no acima exposto, podemos perceber a preocupação do autor em relacionar o jogo às práticas cotidianas que nos possibilitam uma vivência lúdica. Este fato evidencia-se, por exemplo, nos jogos dos sentidos onde escutar uma canção ou assistir a um filme que agrade representam atividades lúdicas.

Pensamos que o uso dos jogos no contexto pedagógico poderia colaborar no processo de aprendizagem, pois, como elucida Luckesi (2015) o ser humano é ativo, o que consequentemente o leva a aprender ativamente, seja ao brincar quando criança, ou, quando adulto, pelos diferentes modos de ação, tais como aqueles que exigem um maior grau de abstração.

Ao possibilitar uma ação mais efetiva, é provável que possamos romper com a passividade dos alunos. Além do mais, é preciso ressaltar que concordamos com Rau (2007), quando ele diz que entendemos que o lúdico como recurso pedagógico deve ocupar um espaço em toda a educação básica, atendendo a necessidades e interesses do educando e do educador no processo de ensino-aprendizagem. (p. 50).

A partir da teoria de Vygotsky, Rau (2007) afirma ser possível a reflexão sobre o lúdico como recurso pedagógico pensando no jogo com vistas ao estímulo do desenvolvimento cognitivo, social, afetivo, linguístico e psicomotor oportunizando aprendizagens específicas; e apresentando aos alunos informações por diferentes tipos de linguagens de modo a atender à diversidade de estilos de aprendizagem.

Seguindo essa lógica, Salvador (2007) declara que:

Uma proposta metodológica que pode auxiliar no processo de mudanças consiste em transmitir os conteúdos de qualquer disciplina por intermédio de atividades que possuam movimento, desafios coletivos, curiosidades, experiências no cotidiano, jogos, entre outros. Possibilitar ações em que Revista Interinstitucional Artes de Educar. Rio de Janeiro, V. 5, N.3- pág. 666-682 set-dez de 2019: "Educação: Corpo em movimento." - DOI: 10.12957/riae.2019.45451 
atividades corporais possam ser realizadas de forma criativa, para que os jovens se percebam enquanto uma totalidade, enquanto cidadão participativo e construtor do seu local e produtor de cultura, [...] (p. 251).

Vale ressaltar que o lúdico no contexto pedagógico não remete à falta de planejamento, pelo contrário, a intencionalidade na conduta do professor é de suma importância. Afinal, Stoltz (2008) nos diz que os conceitos científicos só se desenvolvem com ensino e instrução, porque em sua constituição é fundamental a organização, a sistematização e a intencionalidade de atingir um conhecimento como esse. (p. 67).

Para isso, faz-se necessário conhecer o seu público-alvo percebendo as suas características principais e o contexto no qual está inserido. Visando à construção e aplicação de atividades potencialmente lúdicas adequadas para a realidade do grupo, levando em consideração o tempo, o espaço e os materiais disponíveis.

Além disso, a participação dos alunos nas etapas de planejamento, preparação e confecção dos jogos possibilita a expressão das subjetividades, que nos reporta aos sentidos e significados. Para Vygotsky, o significado remete ao conceito da palavra criado pelo grupo social; já o sentido refere-se ao conceito da palavra para o sujeito, levando em consideração as suas vivências (OLIVEIRA, 1992).

Nessa perspectiva, pensamos que a educação deve ter sentido e significado, de modo a tratar os assuntos acadêmicos relacionados com os contextos dos alunos. O que nos leva a defender espaços de fala para os alunos nos quais eles possam expressar-se por meio das diversas linguagens, pois nesses espaços poderão não só correlacionar os saberes escolares com os pessoais, mas também terão a oportunidade de organizar seu pensamento.

Entendemos, portanto, que as atividades potencialmente lúdicas, tendo como pressuposto as categorias de jogos defendidos por Vial (2015), podem favorecer a existência desses espaços na escola. Ademais, as vivências lúdicas no contexto escolar, ao permitir a interação entre alunos e professores por meio de atividades coletivas, estimulam ainda o desenvolvimento da autonomia, da capacidade de resolução de conflitos, dentre outras questões importantes para a vida em sociedade.

Nesse sentido, Rau (2007) afirma que é necessário que os professores percebam a diversidade de aspectos que podem ser trabalhados através dos jogos, como por exemplo [...] aprender a lidar com a ansiedade; refletir sobre limites; estimular a autonomia; desenvolver 
a atenção e a concentração; ampliar a elaboração de estratégias; e estimular o raciocínio lógico e a criatividade. (p. 53).

Contudo, é preciso cautela na utilização das atividades potencialmente lúdicas como recurso pedagógico para que elas não percam sua função lúdica devido à superação da função pedagógica. $\mathrm{O}$ equilíbrio entre tais funções torna-se essencial.

Este pressuposto dialoga com Luckesi (2002), tendo em vista que este autor reforça a importância de ter como eixo central o sujeito para a compreensão do lúdico. Como a função pedagógica é externa ao sujeito, a sua superação frente às experiências lúdicas individuais na realização de uma atividade pode fazer com que aumente a possibilidade de tal vivência ser compreendida como não lúdica pelos que dela participam.

Desse modo, nossa proposta não tem como objetivo apresentar jogos que venham a iludir os alunos, tal como afirma Massa (2015) [...] o jogo como elemento para iludir a criança, de forma que ela aprenda como se estivesse brincando. (p. 119). O que de fato estamos tentando mostrar é que diversas atividades podem resultar em vivências lúdicas, mas que para isso talvez seja necessária uma mudança de perspectiva sobre o fazer pedagógico.

Assim sendo, acreditamos que as atividades que permitam vivências lúdicas no contexto de sala de aula possam favorecer ao protagonismo do aluno de modo a possibilitar a comunicação entre os saberes escolares e os não-escolares que gera aprendizado com sentido e significado, tendo como objetivo a formação de um sujeito autônomo capaz de pesquisar, analisar e refletir acerca das informações recebidas. Desse modo, sugerimos que o uso das metodologias ativas pode proporcionar uma atuação que conduza a esse objetivo.

Uma vez que, os conceitos de lúdico, ludicidade e vivências lúdicas tendo como pressuposto os estudos de Luckesi (2002, 2014, 2015), bem como a classificação dos jogos proposta por Vial (2015), quando correlacionados aos conceitos de metodologias ativas poderão resultar em propostas de atividades que possam vir a ampliar a possibilidade de vivências lúdicas no contexto escolar.

\section{Metodologias ativas}

Ao pesquisar sobre as propostas que preconizam o aprender como um processo ativo, percebemos que este não é um assunto recente. É possível considerarmos a maiêutica de Sócrates (469 - 399 a.C. $)^{3}$ como um dos primórdios dessa concepção, que consiste em ensinar 
por meio de perguntas (MATTAR, 2017) exigindo dos alunos uma participação mais ativa durante a aprendizagem.

Seguindo a mesma premissa, autores como Dewey e Kilpatrick, com o objetivo de estreitar os laços entre teoria e prática com vistas ao aprendizado contextualizado na perspectiva do aprender para a vida, preconizavam a construção da aprendizagem por meio de atividades práticas a partir de questões cotidianas (CAMARGO \& DAROS, 2018).

Assim, de acordo com Bacich \& Moran (2018):

No início do século passado John Dewey concebeu e colocou em prática a educação baseada no processo ativo de busca do conhecimento pelo estudante, que deveria exercer sua liberdade. Para Dewey, a educação deveria formar cidadãos competentes e criativos, capazes de gerenciar sua própria liberdade (p. 28).

Kilpatrick (2011) - o principal propagador da ideologia de Dewey -, logo procurou manter tais princípios nas suas produções de modo a despertar no aluno a criatividade pela ação por meio do método de projeto. Para ele, a educação tem sua origem na aprendizagem prática transmitida de geração em geração. Contudo, ele declara que, com a institucionalização da educação os saberes escolares, que antes faziam referência aos aspectos práticos e sociais dos alunos, distanciaram-se dos saberes da vida, como reflexo da supervalorização dos saberes teóricos e científicos.

$\mathrm{Na}$ tentativa de estreitar o elo entre estes saberes, o autor pressupõe que o processo de aprendizagem deve basear-se na construção prática por meio da interação entre os pares num ambiente democrático e cooperativo, no qual aprender é adquirir um modo de comportamento. (p.91).

Da mesma forma, Bacich \& Moran (2018) apontam que:

A aprendizagem mais profunda requer espaços de prática frequentes (aprender fazendo) e de ambientes ricos em oportunidades. Por isso, é importante o estímulo multissensorial e a valorização dos conhecimentos prévios dos estudantes para "ancorar" os novos conhecimentos (p. 03).

Sob essa ótica, nos deparamos com o conceito de aprendizagem ativa que se caracteriza pelo processo de aprendizagem decorrente da interação prática entre os envolvidos que, quando associada à aprendizagem reflexiva, amplia a flexibilidade cognitiva superando modelos mentais rígidos e os automatismos, promovendo avanços [...] em espiral, de níveis Revista Interinstitucional Artes de Educar. Rio de Janeiro, V. 5, N.3-pág. 666-682 set-dez de 2019: “Educação: Corpo em movimento." - DOI: 10.12957/riae.2019.45451 


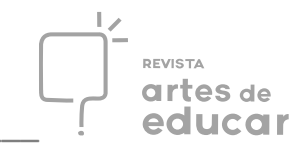

mais simples para os mais complexos de conhecimento e competência em todas as dimensões da vida. (BACICH \& MORAN, 2018, p. 02).

A pedagogia dinâmica tem como foco, dentre outros aspectos, a criatividade, o protagonismo do aluno, a construção do conhecimento e a capacidade de resolução de problemas, utilizando-se para isso das estratégias propostas pelas metodologias ativas (CAMARGO \& DAROS, 2018).

Diante desse cenário, torna-se interessante compreendermos o conceito de metodologias ativas, que de acordo com Bacich \& Moran (2018) caracteriza-se por [...] estratégias de ensino centradas na participação efetiva dos estudantes na construção do processo de aprendizagem, de forma flexível, interligada e híbrida (p.04), corroborando com os pressupostos anteriormente abordados.

Camargo \& Daros (2018) complementam ao dizer que [...] as metodologias ativas de aprendizagem estão alicerçadas na autonomia, no protagonismo do aluno. Têm como foco o desenvolvimento de competências e habilidades, com base na aprendizagem colaborativa e na interdisciplinaridade. (p. 16).

Assim, podemos dizer que as propostas pautadas nas metodologias ativas exigem uma atuação colaborativa de alunos e professores, exigindo que ambos se preparem para a realização das atividades por meio de leituras e pesquisas constantes, sem abrir mão das intencionalidades pedagógicas e do planejamento prévio das atividades.

Tendo em vista as práticas tradicionais enraizadas no fazer pedagógico, acreditamos que a mudança de perspectiva quanto aos papéis desses sujeitos deve se dar progressivamente. Da mesma maneira, acreditamos que não cabe negar a história até então percorrida pela educação, desprezando as metodologias tradicionais de ensino. Por este ângulo, faz-se necessário propor, gradativamente, estratégias voltadas para as metodologias ativas de modo a mesclar as diferentes técnicas, até que alunos e professores estejam mais habituados às especificidades da nova abordagem.

\section{Considerações finais}

Apresentados os conceitos de lúdico e metodologias ativas sentimos a necessidade de promover um diálogo entre eles. Por essa lógica, ressaltamos que, no que se refere ao conceito de lúdico, estaremos seguindo os estudos de Luckesi (2002, 2014, 2015) e de Vial (2015). 


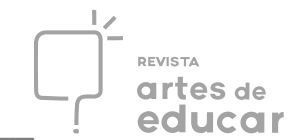

Nesse sentido, as vivências para que sejam classificadas como lúdicas dependem diretamente das experiências individuais construídas ao longo de sua vida. Portanto, iremos nos referir a essas atividades ou vivências como potencialmente lúdicas, tendo em vista seu potencial em proporcionar experiências lúdicas.

Ainda sob essa perspectiva, entendemos que atividades ou vivências que estimulam a imaginação e a criatividade por intermédio de danças, músicas, vídeos, teatralização, poemas e jogos, podem ser consideradas potencialmente lúdicas, tendo em vista a categorização de Vial (2015).

Estudando as metodologias ativas, percebemos que elas têm como foco o protagonismo do aluno, por meio da aprendizagem prática que segue uma trajetória reflexiva e colaborativa mediante estratégias como debates, aulas dialogadas, construção de painéis, aprendizagem em grupo, júri simulado, resolução de problemas, jogos, construção de projetos, dentre outros (MORAN, 2015; ATHAUS \& BAGIO, 2017).

A proposta da metodologia ativa segue os princípios de Dewey e ao correlacioná-la com o conceito de lúdico aqui mencionado, percebemos a autenticação desses ideais, uma vez que, segundo Costa (2012), Dewey faz uma crítica à educação tradicional voltada para a mera transmissão dos saberes e aponta como possibilidade pedagógica a construção da aprendizagem por meio de jogos.

Contudo, Moran (2015) diz que as metodologias ativas precisam seguir objetivos bem definidos, podendo ter o apoio das tecnologias digitais na proposição de desafios e atividades, sendo estes contextualizados a partir dos problemas sociais e que exijam [...] pesquisar, avaliar situações, pontos de vista diferentes, fazer escolhas, assumir riscos, aprender pela descoberta, caminhar do simples para o complexo. (p.18).

Dessa maneira, é possível correlacionar essas características com as dos projetos lúdicos expostos por Vial (2015), no qual se faz necessário elaborar um roteiro que servirá de estratégia para alcançar o objetivo final do jogo. Para teatralizar um poema, por exemplo, o jogador irá demandar das características das metodologias ativas para a elaboração do seu projeto lúdico.

Contudo, para que esses ideais saiam do papel e invadam as salas de aulas torna-se necessário analisar a viabilidade estrutural. No que tange ao ambiente físico de sala de aula, Moran (2015) nos fala que: 
O ambiente físico das salas de aula e da escola como um todo também precisa ser redesenhado dentro dessa concepção mais ativa, mais centrada no aluno. As salas de aula podem ser mais multifuncionais, que combinem facilmente atividades de grupo, de plenário e individuais. Os ambientes precisam estar conectados em redes sem fio, para o uso de tecnologias móveis, o que implica ter uma banda larga que suporte conexões simultâneas necessária (p.19).

Sabemos que essas necessidades exigem um investimento ao qual, possivelmente as instituições públicas de ensino não tenham acesso imediato, tornando necessário um tempo hábil para os ajustes. Porém, algumas adaptações podem ser conquistadas por meio de recursos alternativos, a começar pela organização das salas, onde professores e alunos podem reorganizar as mesas e cadeiras de modo a contemplar as necessidades das atividades a serem realizadas. Na utilização de internet, o professor poderá solicitar que a tarefa seja feita em casa ou ainda contar com a colaboração daqueles que possuem acesso por meio do seu dispositivo móvel.

Ainda com relação ao ambiente escolar, Bacich \& Moran (2018) ressaltam a importância de disponibilizar um ambiente acolhedor, que estimule a participação ativa e a criatividade de todos os ocupantes, sejam alunos ou professores.

A ambientação deste espaço pedagógico combina com uma questão enfática no que diz respeito à prática das metodologias ativas que trata do ensino colaborativo por meio do protagonismo do aluno, possibilitando uma motivação maior por parte dos alunos em participar das aulas, assim como na busca de soluções dos problemas que venham a surgir no decorrer das aulas.

Visto que, como afirmam Bacich \& Moran (2018) a aprendizagem ativa mais relevante é relacionada à nossa vida, aos nossos projetos e expectativas. Se o estudante percebe que o que aprende o ajuda a viver melhor, de forma direta ou indireta, ele se envolve mais. (p. 21-22).

Ao analisar as concepções referentes às metodologias ativas e ao lúdico, observamos um entrelace entre os conceitos que podem viabilizar a prática de atividades pedagógicas por um viés potencialmente lúdico no contexto de sala de aula. 


\section{REFERÊNCIAS}

ALTHAUS, M; BAGIO, V. As metodologias ativas e as aproximações entre o ensino e a aprendizagem na prática pedagógica universitária. Rev. Docência Ens. Sup., Belo Horizonte, v.7, n.2, p. 79-96, jul./dez. 2017. Disponível em: file:///C:/Users/Seven/Downloads/4698-22543-2-PB.pdf Acesso em: 05 jun. 2018.

BACICH, L.; MORAN, J. (Orgs.) Metodologias ativas para uma educação inovadora: uma abordagem teórico-prática. Porto Alegre: Penso, 2018.

BETTI, I. O prazer em aulas de educação física escolar: a perspectiva discente. 1992. 101 f. Dissertação (Mestrado em Educação Física) - Universidade Estadual de Campinas, Campinas, 1992. Disponível em: http://repositorio.unicamp.br/bitstream/REPOSIP/274846/1/Betti_IreneConceicaoRangel_M. pdf Acesso em: 25 jan. 2019.

CAMARGO F; DAROS, T. A sala de aula inovadora: estratégias pedagógicas para fomentar o aprendizado ativo. Porto Alegre: Penso, 2018.

COSTA, V. A ludicidade como estratégia didática para o ensino de matemática. In: ENDIPE, 16., 2012, Campinas. Livro 3. Campinas: UNICAMP, 2012, p. 001163-001174. Disponível em: http://www.infoteca.inf.br/endipe/smarty/templates/arquivos_template/upload_arquivos/acerv o/docs/1660b.pdf Acesso em: 18 out. 2018.

FOUCAULT, M. Vigiar e punir: nascimento da prisão. 20.ed. Petrópolis: Vozes, 1999.

GOMES, C. Brinco, logo existo: o papel da ludicidade na educação escolar. In:

GRANDO, B. (Org.). Corpo, educação e cultura: práticas sociais e maneiras de ser. Ijuí: Unijuí, 2009. p. 111-118.

KILPATRICK, W. Educação para uma sociedade em transformação. Petrópolis: Vozes, 2011.

LIBÂNEO, J. Democratização da escola pública: a pedagogia crítico-social dos conteúdos. 12.ed. São Paulo: Edições Loyola, 1994.

LIBÂNEO, J.; OLIVEIRA, J.; TOSCHI, M. Educação escolar: políticas, estrutura e organização. 10.ed. São Paulo: Cortez, 2012.

LUCKESI, C. Ensinar, brincar e aprender. Aprender - Cad. de Filosofia e Psic. da Educação, Vitória da Conquista, ano IX, n. 15, p. 131-136, 2015. Disponível em: periodicos.uesb.br/index.php/aprender/article/viewFile/5484. Acesso em: 23 jul. 2018

Ludicidade e atividades lúdicas: uma abordagem a partir da experiência interna. In: PORTO, B. (Org). Educação e ludicidade - Ensaios 02, GEPEL, FACED/UFBA, 2002, p.22-60. 
. Ludicidade e formação do educador. Revista Entreideias, Salvador, v.3, n.2, p. 1323, jul./dez. 2014. Disponível em:

https://rigs.ufba.br/index.php/entreideias/article/viewFile/9168/8976. Acesso em: 23 jul.

2018.

MASSA. M. Ludicidade: da etimologia da palavra à complexidade do conceito. Aprender - Cad. de Filosofia e Psic. da Educação, Vitória da Conquista, ano IX, n. 15, p.111-130, 2015. Disponível em: periodicos.uesb.br/index.php/aprender/article/viewFile/5484. Acesso em: 23 jul. 2018

MATTAR, J. Metodologias ativas: para a educação presencial, blended e a distância. São Paulo: Artesanato Educacional, 2017.

MORAN, J. Mudando a educação com metodologias ativas. In: SOUZA, C.; MORALES, O. (Orgs.). Convergências midiáticas, educação e cidadania: aproximações jovens (Coleção Mídias Contemporâneas.), v. 2. Ponta Grossa: UEPG/PROEX, 2015. p. 15-33. Disponível em: http://rh.unis.edu.br/wp-content/uploads/sites/67/2016/06/Mudando-a-Educacao-comMetodologias-Ativas.pdf Acesso em: 08 ago. 2018.

MORIN, E. A cabeça bem feita: repensar a reforma, reformar o pensamento. 21. ed. Rio de Janeiro: Bertrand Brasil, 2014.

OLIVEIRA, L. Violência, corpo e escolarização. Apontamentos a partir da teoria crítica da sociedade. In: OLIVEIRA, M. (Org.). Educação do corpo na escola brasileira. Campinas: Autores Associados, 2006.

OLIVEIRA, M. Vygotsky e o processo de formação de conceitos. In: TAILLE, Y;

OLIVEIRA, M; DANTAS, H. (Orgs.). Piaget, Vygotsky, Wallon: teorias psicogenéticas em discussão. 21.ed. São Paulo: Summus, 1992. p. 23-34.

RAU, M. A ludicidade na educação: uma atitude pedagógica. 20.ed. Curitiba: Ibpex, 2007.

SALVADOR, M.A.S. Corpo e controle no cotidiano escolar: desafios na construção do conhecimento. In: ENFEFE, 11., Rio de Janeiro. Anais... Rio de Janeiro: UFF, 2007, p. 246256.

STOLTZ, T. As perspectivas construtivista e histórico-cultural na educação escolar. 2.ed. Curitiba: Ibpex, 2008.

VIAL, J. Jogo e educação: as ludotecas. Petrópolis: Vozes, 2015.

\footnotetext{
${ }^{\text {i }}$ Mestra em Educação pelo Programa de Mestrado Profissional em Práticas da Educação Básica do Colégio Pedro II. Especialista em Educação Física Escolar pela Universidade Gama Filho. Graduada em Educação Física na Universidade Federal do Rio de Janeiro. Rio de Janeiro, Brasil. E-mail: julianampdesouza@gmail.com, https://orcid.org/0000-0002-8589-2022.
} 
ii Doutor em Educação Física. Especialista em Metodologia do Ensino Superior e Educação Física Escolar. Graduado em Educação Física. Professor titular do Colégio Pedro II, atua no Programa de Mestrado Profissional do Colégio Pedro II - MPPEB/CPII na linha de pesquisa em Práticas da Educação Básica: Linguagens e Letramentos no Ensino Fundamental - Corpo, Escola, Memória e Identidades; e no Ensino Fundamental 1. Professor adjunto da Universidade do Estado do Rio de Janeiro - UERJ, no Instituto Multidisciplinar de Formação Humana com Tecnologias (IFHT), atuando na educação presencial e na EAD. Coordenador do Laboratório de Estudos da Aprendizagem Humana (LEAH) e de Seminário de Práticas Educativas em EAD (Pedagogia). Pesquisador da área de Estudos da Corporeidade e da área de História, Memória e Identidade do Esporte. Professor da UNESA - Curso de Pedagogia. Autor de livros e capítulos de livros na área da Educação e Educação Física, bem como artigos em periódicos e congressos. Orientador de monografias, dissertações e teses em cursos de graduação e pós-graduação. Lecionou em diversas instituições escolares estaduais, municipais e particulares do Rio de Janeiro. Colégio Pedro II. E-mail: marcosantoro@uol.com.br Rio de Janeiro, Brasil, https://orcid.org/0000-0002-1081-4820

3 “O filósofo grego utilizava-se de um método pelo qual não se propunha ensinar diretamente, mas, indiretamente, por meio de perguntas, procurava levar as pessoas com quem conversava a reconhecer que não sabiam o que pensavam saber. Seus diálogos indicavam um caminho, não respostas, para provocar o parto de conceitos naqueles com quem debatia." (MATTAR, 2017, p. 19) 